\title{
New challenges of modern digital society
}

\author{
Maksim Bikalenko, ${ }^{1,}$, Svetlana Vekua $^{2}$, Marina Telegina ${ }^{3}$ and Georgii Khabdaev $^{3}$ \\ ${ }^{1}$ Moscow State Institute of International Relations (MGIMO University), Prospect Vernandskogo, 76, \\ 119454 Moscow, Russia \\ ${ }^{2}$ National Accreditation Agency (NAA), Shabolovka, 33, 115162 Moscow, Russia \\ ${ }^{3}$ Financial university under the Government of the Russian Federation, Leningradskiy prospect, 49, \\ 125993 Moscow, Russia
}

\begin{abstract}
This article lays a particular emphasis on the study of the degree of influence of digitalization and globalization on the formation of trends in the development of modern digital society, on the development of companies and their business strategies. The increasing role of education in the regulation of technological processes by society in the context of the development and implementation of the latest approaches to improving the education system is noted. The importance of integrating the educational and technological spheres into the national processes of socio-economic growth through competent strategic management has been substantiated. The education system demonstrates ways of adapting society to digital challenges.
\end{abstract}

\section{Introduction}

The impact of digitalization and globalization on the emergence of new strategies for the development of a modern digital society is associated with several new entries to the market of digital technologies. First, the activity of introducing technological innovations of enterprises around the world is growing every day, having a significant impact on the economy, including gross domestic product per capita, employment, labor productivity and other factors. As a result, it is extremely important to measure the value of digital technologies, which allow the government to track investments, quantify success and develop strategies for effective economic development and regulations governing the organization of these processes. However, measuring the impact of digital technology on the economy is not that easy. While digital technologies are now ubiquitous and fundamental to society and the development of the business environment, their impact on the digital functioning of the economy is difficult to measure. Measurement of the impact of digital technologies on the economy requires an understanding of the functioning of technological processes at various levels of interaction between objects of the digital environment.

Already in the 1990s, there was a direct link between the emergence of the Internet and the growth of the economy [1]. The situation changed in the 2000s and 2010s, when a

\footnotetext{
* Corresponding author: Msbikalenko@gmail.com
} 
direct link was revealed between economic growth and the use of information and communication technologies (ICT), which are currently actively used in education.

At the same time, we understand digital society as a new relationship between people based on achievements in the implementation and promotion of various technologies used by individuals in the process of production, storage, processing and implementation of knowledge as the highest form of existence of available information.

In this regard, we note the importance of implementing relevant strategies for the development of a digital society by combining the technological, educational, and strategic spheres of the development of a modern digital society to resolve the problem of the economic gap between socio-political and economic development.

\section{Material and methods}

Within this study, we analyzed and systematized information from a number of sources through the use of general scientific methods of cognition, such as data collection and processing, analysis of relevant sources in accordance with the research topic, as well as the use of comparison, analogy, and generalization. The analytical base of the study was the analytical materials of international research agencies, domestic and foreign articles and textbooks, including materials of Russian and foreign scientific conferences, and openaccess Internet materials.

\section{Results and discussion}

\subsection{Managing the technological development of the business environment under digitalization and globalization}

In the second half of the 20th century, globalization began to gain serious momentum, which served as an impetus for the development of a large-scale blurring of borders between countries, people, and generations. Integration and unification have primarily affected the system of economic relations, which increased the importance of the international division of labor, the rate of migration of capital and labor. In this regard, the last decades of the 20th century were marked by the rapid growth of digital transformation, as a result of which fundamental changes for business, society, and the global economy have taken place. After the global crisis of 2008-2009, digital industries have been the most dynamic and promising areas of development in the global economy. Nevertheless, today there is an acute imbalance between benefits and risks in the digital economy, which is due to the need for global governance in this area.

By the early 21 st century, the first rudiments of Internet technologies began to appear, which almost immediately influenced the course of economic processes. Subsequently, digitalization has been closely intertwined with globalization, forming a powerful integration force. Due to the rapid growth of Internet technologies, the 21 st century can become the century of digital technologies, globalist transformations, reorganization and universal digitalization of economic processes. The common name for these processes is the definition of "digital economy" [2]. These technologies have made it possible to reduce both the distance any information must travel to its addressee and the time to process it.

Digitalization is a transformative and powerful driver of globalization. In everyday life it is manifested in the use of digital technologies such as the Internet and smartphones. All this made the information processing more reliable, timely, and accurate. This phenomenon is global: since 2005, the number of Internet users worldwide has tripled, and the number of users in developing countries has reached 3.2 billion [3]. 
A more detailed study found other ways of manifestation:

- mobile communications: today 5.22 billion people use a mobile phone, which is 66.6 percent of the global population. Unique mobile users have grown by 1.8 percent ( 93 million) since January 2020, while total mobile connections increased by 72 million ( 0.9 percent) and reached 8.02 billion in early 2021 [4];

- Internet technologies: in January 2021, 4.66 billion people worldwide were Internet users, which is 316 million people (7.3\%) more than in the same period of the last year. Global Internet penetration has now reached 59.5\%;

- social networking services now have 4.2 billion users in the world. During 2020, this figure increased by 490 million, delivering more than 13 percent year-on-year growth. The number of social media users is now equivalent to more than 53 percent of the global population.

None of the countries can now take a liberty to cut off access to global flows, while narrow export strategies are already losing the real value of globalization: the flow of ideas, talent, and resources that drive innovation and productivity. Digital globalization further complicates political choices. Value chains are shifting, new hubs are emerging, and economic activities are transforming. This transition creates new opportunities for countries to benefit from their role in the global economy [5].

The effect of digitalization is critical for the internationalization of new venture capital projects, as technological change is the basis for rapid internationalization. The technological change over the past two decades has triggered the rapid internationalization of emerging startups. According to some experts, globalization has led to lower transaction costs as a result of internationalization and advances in communication and transport technologies.

In the face of such technological changes, the international business environment helps small and medium-sized enterprises to seize their opportunities for development at early and rapid internationalization. Thus, digitalization for a small firm is an additional opportunity to become a member of the international market [6]. Moreover, entrepreneurs now do not experience an urgent need to purchase a server, recruit a team of IT engineers and develop their own virtual sites from scratch; now all this is affordable at a lower cost.

Digitalization smoothly complements globalist processes in several ways [7]:

- an increasing use of digital platforms leads to lower costs of cross-border transactions, allowing businesses to communicate with customers and suppliers in any country;

- the positive aspects of globalization had been most characteristic of large transnational corporations, while now small and medium-sized enterprises also have the opportunity to participate in international trade.

Due to growing competition, less developed countries also have got the opportunity to develop the economic potential of their multinational companies. For this, however, society needs to learn how to properly manage the digital economy, which is of paramount importance for eliminating the gaps in the economic and technological adaptation of developing countries in comparison with developed countries, as well as for solving cybersecurity problems and the low quality of life of the population. At the same time, the G20 has limited experience in strategic management of economic development but united under its leadership countries with different levels of digital development, including those lagging behind, which can play a large role in the global strategic management of the digital economy.

The fourth wave of the industrial revolution (Industry 4.0) is creating a digital space that connects the virtual and physical worlds. Information and communication technologies are becoming the backbone of this evolution. Today, more than ever, the future of countries depends on how national governments can coordinate digital activities between businesses and individuals. This political goal equally concerns a number of issues, such as the 
development of the Internet infrastructure, the organization of legal regulation of technological interaction processes, the readiness to do business under the development of a digital society, consumer expectations and preferences of subjects of the digital environment, etc. Policymakers have to design policies that can support the development of basic infrastructure in close collaboration with other stakeholders, such as business, academia, individuals, while being able to define universal long-term goals for technological development towards achieving leadership in the market in the context of adaptation of the environment to new challenges.

However, digitalization is an ongoing process that dictates a new reality of economic development in the context of the global integration of technological development processes. National governments must accelerate the pace of development in strategic management, which would primarily be aimed at creating an increasingly sophisticated infrastructure suitable for the growth of the potential of the digital economy. The ability to expand a business with infrastructure in the digital economy cannot be considered. Having a highly developed infrastructure is not enough for further digitalization.

Thus, there is a need to create an ecosystem for the systematic introduction of advanced innovations [8] and relevant business strategies in the management of modern companies operating in a digital environment.

\subsection{Achieving technological leadership in a digital business environment}

Globalization and digitalization have a significant impact on modern companies. The use of various modern technologies, such as automation (robots), artificial intelligence, and the Internet of Things, can significantly increase the business performance of a company.

In 2020, in the context of the COVID-19 pandemic, companies engaged in digital transformation of internal processes were most resistant to crisis manifestations, while other companies had to accelerate digitalization processes to adapt to new conditions. At the same time, these changes in many companies are temporary. Thus, according to $\mathrm{PwC}$ and ABBYY DIGITAL IQ 2020 joint research, 46\% of Russian companies did not make significant changes into their business strategies [9]. The transition of employees to remote work and the active use of digital technologies associated with this process showed the inefficiency of the organization of work in some companies, which led to the optimization of the number of employees and their work schedule.

According to the conclusions made in the Wearesocial Digital 2021 special report, some of employees will continue to work remotely [9]. This fact allows us to conclude about the persisting trends towards digital transformation of companies. In this regard, the most promising projects for modern companies, in our opinion, will be projects related to automation and robotization (the use of artificial intelligence), as well as projects aimed at the development of cloud technologies and cybersecurity. Moreover, the development of cloud technologies and cybersecurity are the most significant in the transition of employees to remote work, since the risks of leaks and damage to information in modern conditions have increased significantly.

During the Artificial Intelligence Journey (AI Journey 2020), speaking "Artificial intelligence as the main technology of the XXI century", the President of the Russian Federation V.V. Putin said that Russian companies need to use advanced artificial intelligence technologies, as well as apply big data analysis to improve the production and management performance [11].

The authors of "Trends and Technologies 2030", a study by the Digital Leader Networking platform, tried to identify the most promising and demanded technologies for the next 10 years, as well as their impact on the technological development of Russian companies. According to this study, the use of artificial intelligence and machine learning 
technologies will have the greatest impact on changes within companies. The authors also concluded that by 2030 more than $50 \%$ of the staff of companies will be at remote work, and up to $50 \%$ of company employees will be replaced by artificial intelligence [12]. This study shows that the changes caused by the 2020 crisis are conceptual and the management of companies must consider these trends when planning the company's strategy.

Currently, digital ecosystems seem for us to be most effective business model in terms of forming a digital strategy. A strategic approach to innovation enables digital ecosystems to be the most flexible and efficient in adapting to external conditions. This fact confirms that the leaders in terms of capitalization among non-resource companies in Russia are SBER and Yandex digital ecosystems.

Striving for digital leadership, companies often face challenges and barriers that prevent them from benefiting from innovation; and the lack of a strategic approach in shaping the digitalization of company processes, in turn, is the main reason for the setbacks faced by companies in digital transformation. Thus, it is worth noting that the overall corporate strategy of the company should include a digital strategy containing the specific goals and objectives required to achieve the digital transformation of the company. The most common mistake of the company's management, as a rule, is the lack of specifics in defining goals and understanding the essence of the concept of digital transformation, as well as refusal to develop a digitalization roadmap for the company [13]. Due to the systematic emergence of similar problems, the authors of DIGITAL IQ 2020 have identified a number of barriers to digital transformation [9]:

1) lack of skills to implement and manage innovations;

2) resistance of company employees to innovations (changes);

3) lack of understanding of the economic and other effect of the introduced innovations among the management;

4) high cost of innovation (financial incapacity).

To overcome these barriers, we believe it necessary to:

1) form the corporate culture of the company with the involvement of employees in the digitalization process;

2) upgrade skills of company employees through active participation in corporate training programs, for example, using LMS (Learning Management System) platforms;

3) hire digital transformation leaders (analysts and consultants) / involve independent experts in the digitalization process with successful experience in project implementation, strategic management of these projects, aimed at the digital transformation of organizations;

4) use modern solutions in process analytics (Processmining) to analyze the company's activities.

In general, the systematic professional development of the company's employees and the development of corporate training programs can significantly simplify the implementation and adaptation of digital technologies in the company. In this regard, we should note that the development of the education system following modern trends is one of the keys to the successful implementation of digital transformation in companies. Further, we believe it necessary to consider the trends in the development of the education system in the context of the formation of a digital society.

\subsection{Formation of an updated education system under digitalization}

Social and economic changes and new technological challenges have necessitated the development of new approaches to decision-making to improve the education system, including the system of education quality assessment. Today, the role of education in the formation of a personality is especially relevant, and social changes in an individual 
directly affect the change in the social structure of society. As a result of massive digitalization, growing urbanization and changes in human intelligence, society must change. Education is the root cause of social and cultural changes taking place in society, education in our time, as well as many centuries ago, is used as a means of socialization of the younger generation in order to meet the expectations of society in various areas of development [14]. Education largely follows trends in technological development, which becomes especially important in the era of digitalization [15].

That is why it becomes especially important to be able to quickly adapt to new opportunities and risks, as well as to be an innovator, increasing the level of human capital development. The use of information and communication technologies (ICT) creates a powerful learning environment and transforms the learning and teaching process making learners independently use their knowledge. ICT is not just a tool that can be added to existing teaching methods but also an important method of supporting new ways of teaching and learning. In the 21 st century, the term "technology" is used in many fields, including education. This is due to the fact that technology has become a main line for the transfer of knowledge in most countries. Technological integration has now undergone innovation and transformed our society, which has completely changed the way people think, work, and live. In these conditions, educational organizations that must prepare students for life in a "knowledge society" must remember on the integration of ICT into their curricula.

The education quality assessment system, in turn, is also important for making the right decisions in the formation of directions for the development of state policy of various states in education. The education quality assessment system must meet criteria such as openness, transparency, accessibility, objectivity, and independence. It is worth noting that the modern education system provides for the introduction of digital technologies that will reveal these criteria. For example, to make high-quality education accessible and affordable to the population throughout Russia we need to use a modern information base in educational institutions; and to make the education quality assessment system accessible, fair and transparent we need to widely introduce digital technologies into the educational environment, which is necessary for effective operation of tools of managerial decisions.

Digitalizing the monitoring operations will significantly reduce the time for data processing. In addition, modern digital technologies require actively developing human resources in the educational environment: introduce a system of additional development of professional competencies in digital technologies, learn to apply digital thinking systematically and timely upgrade skills, take part in professional staff retraining.

Monitoring statistics of educational organizations based on federal statistical observations shows a sharp leap in development over the past two years of educational programs implemented with e-learning and distance learning technologies, which require a developed information base of the educational organization [16-20].

Currently, not every educational provider is ready to fully accept the current trends in the development of the education system in the digital environment. According to federal statistics, some educational institutions still do not have access to the global Internet, and some of them do not have an official website, including on educational online resources, services, and platforms [16-19, 21]. Besides, most educational organizations practice restricting access to information on official websites on the conduct of the educational process, data on scientific activities. In the context of the digitalization of the educational environment, there is a growing need for affordable, high-quality education based on the desire of educational organizations to comply with the status of a modern and accessible institution of education.

To become a modern educational institution, education providers are actively developing new educational tools, such as mass, open online education, for which platforms 
of new educational resources and open online learning courses are being developed. Continuing education is actively gaining momentum in development and occupies one of the important places in the modern education system. Continuing education of children and adults is increasingly perceived now as one more condition for quality education $[17,21]$.

The most popular now are virtual education institutions that provide an opportunity to study with foreign students, who do not need now to travel abroad, which helps regulate the process of global internationalization of the education system. A special place in the system of virtual education today is occupied by the network form of education, which allows virtual educational organizations to become transnational due to the involvement of educational institutions around the world in the global educational process [16-20].

The use of these educational resources helps develop educational programs that are focused on the individual needs of students.

Education is the most powerful tool for social change. With education, society can make the desired changes and modernize, teach professionals to think strategically in a constantly changing socio-economic environment, and introduce the latest technological changes at a high speed. Education can transform society by providing opportunities and experiences to help an individual improve in accordance with the emerging needs and philosophy of a changing society. Sustainable social progress requires careful planning in all aspects of life - social, cultural, economic, and political and the high adaptability, which will help to skillfully maneuver in the face of a crisis, an acute shortage of technological, economic, and human resources, as well as through the constant development of the ability to strategic thinking. At the same time, education should keep pace with the current development trends inherent in various countries and institutions due to the peculiarities of their socioeconomic development.

\section{Summary}

Lack of a balanced focus on global processes, new business strategies and new forms of human capital development will put a modern digital society to the path of new contradictions, strengthened with digitalization. Therefore, we believe the search for the correspondence of each of the selected factors to become a strategic choice for digital transformations and the basis for sustainable development, for example, small and mediumsized enterprises follow three main directions of transition to digital technologies: accelerating digitalization, digitalizing sales functions and finding digital partners for market entry [22]. In this context, the decision to choose one of the three ways of digital transformation is determined by the existing level of digital maturity, the level of education, the history of the introduction of digital technologies, etc.

Modern society is now in transition to the digital economy, which is manifested in the acceleration of scientific and technological progress, the growth of the role of innovations, changes in the business processes of companies, and the qualitative composition of human resources. Changes in the economy entail changes not only in technological processes but also in the culture of management, worldview, attitudes towards personnel, as well as the mentality of the employees themselves, the cultural and social environment of the company. A modern leader needs to consider these trends and strive for a systematic improvement of the qualifications and competencies of both his own and the company's employees. It is also necessary to focus on a strategic approach to digital transformation, namely, to create a digital strategy and a digitalization roadmap for the company.

The development strategy in science and technology should be organized in such a way as to actually solve the problem of the long-term gap between socio-political and economic planning, science and technology in tandem with the goals of development plans through its practical application. Building this kind of strategy is based on the development of a new 
world that will build a large, strong, diversified, sustainable, and competitive economy able to ensure a high standard of living for its citizens. It must be designed to provide a solid platform for commitment to science, technology and innovation with person-oriented economic transformation.

Thus, it is obvious that education, technology and their integration into national processes of socio-economic growth through competent strategic management should be of the highest priority for any company or state to be able to change its economy, considering the available resources and opportunities, and to take its rightful place in the community of leading countries with developed economies. The government should encourage the creation and strengthening of organizations, institutions, and agencies for the development of science and technology, facilitating the process of acquiring knowledge for the adaptation, use, and diffusion of technologies in various areas of socio-economic development both in the public and private spheres.

\section{References:}

1. A. Mentslev, M.V. Engel, Conference: International Scientific Conference "Far East Con" (ISCFEC, 2020)

2. K. Barefoot, US Department of Commerce Bureau of Economic Analysis, Washington, DC, 15 (2018)

3. T. Elkjaer, J. Damgaard, 16th Conference of the International Association of Official Statisticians (2018)

4. The Digital 2021 Global Overview Report (2021) https://wearesocial.com

5. J. Bughin, S. Lund, J. Manyika, The McKinsey Quarterly (2016)

6. Y.Y. Lee, International Business Research, 12(4), 11 (2019)

7. Digital globalization: the new era of global flow (2021) https://www.mckinsey.com/

8. E. Sepashvili, Economia Aziendale Online, 11(2), 191 (2020)

9. DIGITAL IQ 2020 (2021) https://www.pwc.ru

10. Wearesocial (2021) https://wearesocial.com

11. Results of Artificial Intelligence Journey (AI Journey 2020) (2021) http://www.kremlin.ru

12. Trends and technologies (2021) https://ict.moscow/

13. I.N. Kosareva, V.P. Samarina, Bulletin of Eurasian Science, 11(3) (2019)

14. Education as an instrument of social change and enhancing teaching-learning process with the help of technological development, https://www.researchgate.net

15. P.I. Kasatkin, J.A. Kovalchuk, I.M. Stepnov, Voprosy Ekonomiki, 12, 123 (2019)

16. State federal statistical monitoring forms for higher education, 1-2 (2021) https://www.minobrnauki.gov.ru

17. State federal statistical monitoring forms for continuing professional education, 1-PK (2021) https://www.minobrnauki.gov.ru

18. State federal statistical monitoring forms for general education, 001 (2021) https://edu.gov.ru

19. State federal statistical monitoring forms for secondary and vocational education, SPO1 - SPO-2 (2021) https://edu.gov.ru

20. State federal statistical monitoring forms for vocational education, https://edu.gov.ru 
21. State federal statistical monitoring forms for continuing education of children, 1-DO (2021) https://edu.gov.ru

22. S. Chakraborty, B. Chakraborty, V. Singh Dahiya, L. Timajo, Conference Paper (2018) 